\title{
Effect of Learning Styles on Peer Assessment in an Agent-based Collaborative Learning Environment *
}

\author{
Chung Hsien Lan $^{1}$, Sabine Graf ${ }^{2}$, K.Robert Lai ${ }^{3}$, Kinshuk ${ }^{4}$ \\ ${ }^{1,3}$ Department of Computer Science and Engineering, Yuan Ze University, Taiwan \\ 1chlan@nanya.edu.tw, ${ }^{3}$ krlai@cs.yzu.edu.tw \\ ${ }^{2}$ Women's Postgraduate College for Internet Technologies, Vienna University of Technology, \\ Austria, sabine.graf@ieee.org \\ ${ }^{4}$ Athabasca University, 1 University Drive, Athabasca, AB T9S 3A3, Canada \\ kinshuk@ieee.org
}

\begin{abstract}
In peer assessment, the awarding grades might not accurately reflect the students' achievement due to potential rating bias or individual abilities. The proposed methodology aims at aggregating students' ratings to reduce personal bias using agent negotiation. We consider individual learning styles of assessors into the negotiation process and show by an illustrative example and an experiment how the accuracy of assessment results can be improved through incorporating learning styles. The more accurate feedback provides students a better quality of assessment which enables them to reflect their effort and abilities.
\end{abstract}

\section{Introduction}

Peer assessment enhances student interpretation and reflection, enabling instructors to improve their understanding of student performance [1]. Students are capable of learning how to criticize peer work and accept peer criticism, thereby developing their critical thinking skills and self-reinforcement through peer assessment [2]. However, the issue of fairness has to be considered in peer assessment due to students' individual characteristics, preferences, experiences, abilities, social styles, and learning styles [3][4][5]. The awarding grades might not accurately reflect students' achievement due to potential rating bias or individual abilities. Therefore, this study presents a novel methodology that can aggregate students' ratings to

* This research has been funded partly by the Austrian Federal Ministry for Education, Science, and Culture, the European Social Fund (ESF) under grant 31.963/46-VII/9/2002, and the National Science Council of R.O.C. under grant number NSC 95-2745-E-155007-URD. reduce personal bias. Furthermore, individual learning styles of students who give ratings are considered into the assessment process in order to enhance the accuracy and fairness of the assessment. The aggregated assessment considering students' learning styles provides students a better feedback.

\section{Effect of Learning Styles on Peer Assessment}

The process of peer assessment requires cognitive activities such as reviewing, summarizing, clarifying, providing feedback, diagnosing errors, and identifying missing knowledge or deviations. However, each student has an individual learning style and thus has different abilities to assess peers' work. The aim of our study is to include learning styles in the peer assessment process in order to improve the quality of grading. To support peer assessment and consider learning styles, an assessment agent which relies on fuzzy constraints and agent negotiation [6] is used. During the process of peer assessment, students define individual fuzzy membership functions based on their assessment issues and agents facilitate student-student negotiations.

In this study, we adopt the specific assessment issues that include Creativity, Completeness, Execution, and Security, and extend the assessment agent by considering the effect of learning styles. Looking at adaptive educational systems which incorporate learning styles, Felder-Silverman learning style model (FSLSM) [7] is one of the most often used model in recent times and some researchers even argue that FSLSM is the most appropriate model [8][9]. FSLSM characterizes each learner according to four dimensions: active/reflective, sensing/intuitive, visual/verbal, and sequential/global. Two of the four dimensions of FSLSM are of particular interest according to the 
specific assessment issues (Creativity, Completeness, Execution, and Security): active/ reflective and sensing/ intuitive.

The active/reflective dimension distinguishes between an active and a reflective way of processing information. Since execution and security deals with actively testing whether the implemented solution works and respectively checking security settings, active learners tend to be more familiar with these issues. Thus, the importance of the assessment issues Execution and Security provided by active students can be seen as higher than by reflective students.

Sensing learners prefer to learn concrete material and tend to be more practical, thus their ratings in Completeness are accounted as more important. On the other hand, intuitive learners prefer to learn abstract material. They like to discover possibilities and relationships and tend to be more innovative and creative than sensing learners. Therefore, we assume a higher importance for ratings on the Creativity issue.

\section{Illustrative Example}

We present the process of peer assessment by a typical scenario and illustrate how learning styles can enhance the quality of assessment results. In this example, three students (student $I, J$ and $K$ ) are taking part in peer assessment. Student $K$ submits his project and performs self assessment on his project. Students $I$ and $J$ assess independently student $K$ 's project as well. Students $I, J$ and $K$ are allowed to construct their own fuzzy membership functions for the specific assessment issues (Creativity, Completeness, Execution, and Security) to assess the project. The process of peer assessment is divided into the following steps.

\section{Classifying Students' Learning Styles}

Students $I, J$ and $K$ fill out the ILS questionnaire [10] in order to identify their learning styles. Based on the feedback, student $I$ is found to be an active and intuitive learner, student $J$ a reflective and intuitive learner, and student $K$ an active and sensing learner.

\section{Defining the Fuzzy Constraints}

Students $I, J$ and $K$ define membership functions for each assessment issue to assess student $K$ 's project. Each membership function is considered as a fuzzy constraint (Figure 1).

\section{Adjusting importance of assessment issues}

According to learning styles, each agent adjusts the importance of assessment issues for each student. Through considering the importance and computing the degree of satisfaction for each agent, the fuzzy membership functions are adjusted as can be seen in Figure 2.

\section{Adopting Negotiation Strategy}

Assessment agents $I, J$ and $K$ represent students $I, J$ and $K$ respectively to model a multi-issue negotiation.
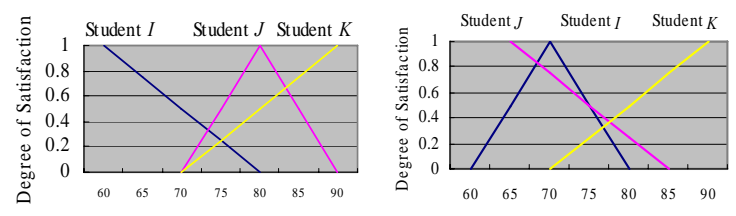

Creativit
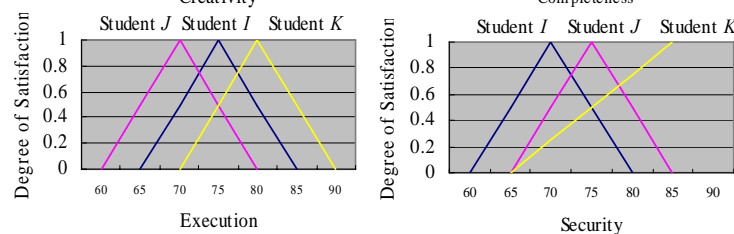

Figure 1. Fuzzy constraints
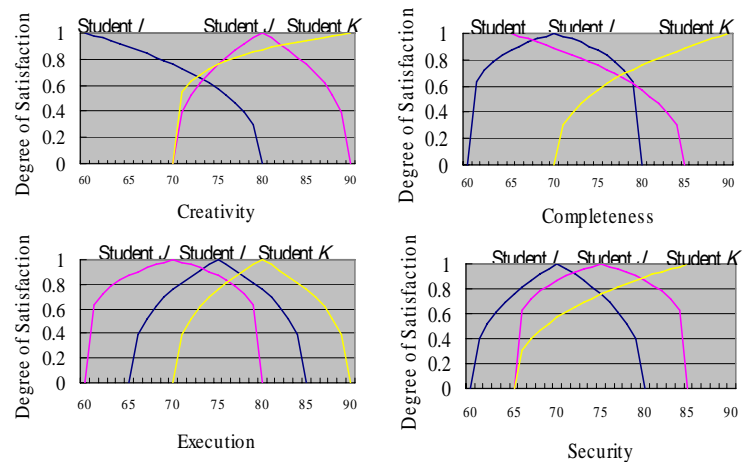

Figure 2. Adjusted fuzzy constraints

Agreement is achieved when all participants agree. Agents $I, J$ and $K$ take turns attempting to reach an agreement. Agent $I$ proposes its assessments $u_{1}^{I}=(60,70,75,70)$ related to Creativity, Completeness, Execution, and Security at threshold $\alpha_{1}^{I}=1$. However, the overall degree of satisfaction for agent $J$ is 0 and for agent $K$ is 0 as well. Therefore, agents $J$ and $K$ can not accept $u_{1}^{I}$ as an agreement. Subsequently, agent $J$ and $K$ propose their offers $u_{1}^{J}=(80,65,70,75)$ and $u_{1}^{K}=(90,90,80,85)$ at threshold $\alpha_{1}=1$. However, other agents still can not accept one of these offers as an agreement.

Furthermore, assuming agent $K$ adopts the concession and trade-off strategies and has no expected proposal at threshold $\alpha_{1}^{K}=1$, agent $K$ lowers its threshold to the next threshold $\alpha_{1}^{K}=0.9$ and creates a new set of feasible proposals $v_{2}^{K}$ to negotiate:

$$
\begin{aligned}
& v_{2 a}^{K}=(82,90,80,85), v_{2 b}^{K}=(90,85,80,85), \\
& v_{2 c}^{K}=(90,90,7885), v_{2 \mathrm{~d}}^{K}=(90,90,80,80)
\end{aligned}
$$

According to a normalized Euclidean distance, which can be applied in measuring the similarity between alternatives to generate the best offer [6], the similarity among these feasible proposals was computed by agent $K$, and agent $K$ selected the most likely acceptable solution $v_{2 c}^{K}=(90,90,78,85)$ as the offer for agents $I$ and $J$. This procedure of offer evaluation and 
generation for agents $I, J$ and $K$ continues until an agreement is reached or no additional solutions can be proposed.

\section{Producing the Final Result}

Through several rounds, negotiation finally reached an agreement over (Creativity, Completeness, Execution, Security) at (73, 78, 77, 74). The agreement shows that the proposed approach, involving fuzzy constraint relaxation and similarity, helps the assessment agent in arranging assessment criteria to meet each agent's needs, and assists agents in reaching an agreement that maximizes the overall degree of satisfaction for assessments in the multi-issue negotiation. Furthermore, the assessment agent reduces rating bias based on individual abilities and therefore improves the accuracy of peer assessment. Finally, student $K$ gets the more accurate feedback to reflect and improve his project.

\section{Experiment}

We used the peer assessment system to help thirteen undergraduate students to do peer assessment in the course Database System. These students were randomly divided into four groups, where each student assessed the work of his/her group mates and his/her own work. However, students did not know the identity of their group mates. Through filling out the ILS questionnaire, 4 students are classified as active and sensing students, 3 as active and intuitive students, 4 as reflective and sensing students and 2 as reflective and intuitive students. During the peer assessment process, all students submitted their projects and moved on to peer and self assessment using the evaluation concepts provided by the instructor via the assessment agent. The instructor also rated the submitted projects. Pearson's correlation analysis was adopted to compare the correlations between the resulting ratings of peer assessment and instructor's ratings. Results are presented in Table 1.

\begin{tabular}{c|cc}
\hline $\begin{array}{c}\text { Assessment } \\
\text { issues }\end{array}$ & $\begin{array}{c}\text { Peer assessment } \\
\text { without learning } \\
\text { styles }\end{array}$ & $\begin{array}{c}\text { Peer assessment } \\
\text { with learning } \\
\text { styles }\end{array}$ \\
\hline Creativity & $0.552^{*}$ & $0.571^{*}$ \\
Completeness & $0.451^{*}$ & $0.619^{*}$ \\
Execution & $0.531^{*}$ & $0.742^{* *}$ \\
Security & $0.483^{*}$ & $0.695^{* *}$ \\
\hline
\end{tabular}

Table 1. Correlation analysis between the instructor and students' ratings $\left(*: \mathrm{p}<0.05,{ }^{* *}: \mathrm{p}<0.01\right)$

Students' assessments considering learning styles are more significantly and positively correlated with the instructor's assessments for each assessment issue. Therefore, the findings indicate that students' learning styles can influence the process of peer assessment positively and the final scores are more consistent with the instructor's assessments.

\section{Conclusion}

Our experimental results show that the negotiated agreement considering students' learning styles indeed contributes to provide students a better quality of assessment. Through the mechanism of agent negotiation, students can acquire an objective assessment by considering assessments of all raters and the ratees. The negotiated agreement provides students with superior assessments, thereby enhancing learning effectiveness. In addition, all participants also thought that by relying on agent negotiation and learning styles, the assessment method was flexible and fair.

\section{References}

[1] Ford, K., Bradshaw, J., Adams-Webber, J., and Agnew, N., "Knowledge Acquisition as a Constructive Modeling Activity", International Journal of Intelligent Systems, 1993, pp. 9-32.

[2] Liu, C.C., Liu, B.J., Hui, T.A., and Horng, J.T., "Web Based Peer Assessment Using Knowledge Acquisition Techniques: Tools for Supporting Contexture Awareness", International Conference on Computers in Education, New Zealand, 2002.

[3] Lin, S.S.J., Liu, E.Z.F., and Yuan, S.M., "Web-based Peer Assessment: Feedback for Students with Various ThinkingStyles”, Journal of Computer Assisted Learning, 2001, 17 (4), 420-432.

[4] May, G..L., and Gueldenzoph, L.E., "The Effect of Social Style on Peer Evaluation Ratings in Project Teams”, Journal of Business Communication, 43, 2006, pp. 4-20.

[5] Sherrard, W.R., and Raafat, F., "An Empirical Study of Peer Bias in Evaluations: Students Rating Students”, Journal of Education for Business, 70(1), 1994, pp. 43-47.

[6] Lai, K.R., and Lan, C.H., "Modeling Peer Assessment as Agent Negotiation in a Computer Supported Collaborative Learning Environment”, Journal of Educational Technology \& Society, 9(3), 2006, pp.16-26.

[7] Felder, R.M., and Silverman, L.K., "Learning and Teaching Styles in Engineering Education”, Engineering Education, 78, 1988, pp. 674-681. Preceded by a preface in 2002: http://www.ncsu.edu/felderpublic/Papers/LS-1988.pdf (retrieved 23 July, 2005).

[8] Carver, C.A., Howard, R.A., and Lane, W.D., "Addressing Different Learning Styles Through Course Hypermedia”, IEEE Transactions on Education, 42, 1999, pp. 33-38.

[9] Kuljis, J., and Liu, F., "A Comparison of Learning Style Theories on the Suitability for Elearning”. In M. H. Hamza (ed.), Proceedings of the IASTED Conference on Web Technologies, Applications, and Services, ACTA Press, 2005, pp. 191-197.

[10] Felder, R.M., and Soloman, B.A., Index of Learning Styles Questionnaire, 1997. Retrieved 30 April, 2006, from http://www.engr.ncsu.edu/learningstyles/ ilsweb.html. 